\title{
Electrocatalytic oxidation of hydrazine by copper iodide modified sol-gel derived carbon-ceramic composite Electrode
}

\author{
Ghasem Karim-Nezhad* and Naeemeh Alipour
}

Department of Chemistry, Payame Noor University, PO BOX 19395-3697 Tehran, Iran

\begin{tabular}{l}
\hline C H R O N I C L E \\
\hline Article history: \\
Received January 22, 2014 \\
Received in revised form \\
February 02, 2014 \\
Accepted 28 May 2014 \\
Available online \\
5 June 2014 \\
\hline Keywords: \\
Copper iodide \\
Ceramic-carbon composite \\
electrode \\
Electrocatalytic oxidation \\
Hydrazine \\
Cyclic voltammetry
\end{tabular}
\begin{abstract}
A B S T R A C T
A new sol-gel derived ceramic-carbon composite electrode was fabricated by the use of $\mathrm{CuI}$ as modifier. The electrocatalytic activity of the copper iodide modified sol-gel derived ceramiccarbon composite (CIM-SGD-CCC) electrode was examined for the oxidation of hydrazine. Cyclic voltammetry was employed to study the electrochemical and electrocatalytic properties of the modified electrode. Results showed that the CIM-SGD-CCC electrode has very high catalytic activity for electrooxidation of hydrazine. This proves that the copper iodide bears the main role in electro-catalytic oxidation of hydrazine. This modified electrode shows fast amperometric response with the range from $1 \mu \mathrm{mol} \mathrm{L}^{-1}$ to $40 \mu \mathrm{mol} \mathrm{L}^{-1}$ and the limit of detection (LOD) of $0.524 \mu \mathrm{mol} \mathrm{L}^{-1}$ for hydrazine. The relative standard deviation (R.S.D.) was $0.72 \%$ for 5 successive assays. High stability, good reproducibility, rapid response, easy surface regeneration and fabrication are the important characteristics of the proposed electrode.
\end{abstract}

\section{Introduction}

Although metals such as $\mathrm{Pt}, \mathrm{Au}$, and $\mathrm{Ag}$ are very active in the anodic oxidation and cathodic reduction, they are too expensive for practical applications. ${ }^{1,2}$ The use of bare electrodes for electrochemical investigations have a number of limitations, such as low sensitivity and reproducibility, slow electron transfer reaction, low stability over a wide range of solution composition and high overpotential at which the electron transfer process occurs. Many attentions are focused on modified electrodes. Chemically modified electrodes (CMEs) have played an important role in the studies of electrocatalysis ${ }^{3-5}$ electron transfer kinetics, ${ }^{6}$ membrane barriers ${ }^{7}$ and electroorganic synthesis. ${ }^{8}$ In operation, the redox active sites shuttle electrons between the analyte and the electrodes with significant reduction in activation overpotential. To prepare the CME, most often a thin film of selected chemical is either bound or coated on to the electrode surface to endow desirable properties of the film in rationally and chemically designed manners.

\footnotetext{
* Corresponding author. Tel.: +98 461 2349868, Fax: +98 4612332556

E-mail address: g.knezhad@gmail.com (G. Karim-Nezhad) 
The development of chemically modified electrodes (CMEs) made by insoluble inorganic modifiers is motivated by their potential applications and usage in the field of electrocatalysis, electrochromism, solid-state batteries, electrode materials, and electroanalytical applications. These inorganic materials must gain acceptance in practical applications after high chemical and electrochemical stability along with a simple preparation.

However, the main problem is that it is difficult to maintain long-term stability, since the electrochemical activity of modified electrode gradually decreases due to the detachment and dissolution of the catalyst from the substrate. In addition, the activity of modified electrode decreases quickly by accumulation of chemisorbed intermediates, which block the catalyst surface. In order to achieve electrode with high sensitivity and long-term stability and to develop a simple method for preparing a modified electrode, sol-gel technique has been developed. ${ }^{9-16}$ Now, the sol-gel process conducted in the presence of graphite powder was proposed for the fabrication of carbon ceramic electrodes (CCEs) as a new kind of carbon substrates in electrochemical systems. Considering the stability, permeability, simplicity, versatility, physical rigidity, transparency, porosity, efficient encapsulation, and flexibility in the fabrication procedure of carbon-ceramic substrate, it is one of the best materials that can be used as catalyst supporter. ${ }^{9,}{ }^{10}$ The sol-gel method offers a possibility of preparing glassy material at room temperature that can support the immobilization of different mediators and reagents. These special properties of modified carbon ceramic electrodes (CCEs) have attracted a lot of attention.

Recently, the sol-gel derived ceramic carbon composite electrodes (CCEs) have become increasingly used for the fabrication of effective electrochemical sensors. ${ }^{9}$ The composite electrodes are prepared by mixing carbon with the organically modified silicates (or mosils) and the resultant mixture is packed into a tube or spread on a suitable surface. It is therefore possible to dope the ceramic composite with a wide variety of reagents or catalysts to fabricate the desired sensing material.

We recently reported copper chloride ${ }^{17}$ and copper bromide ${ }^{1}$ modified copper electrodes. In these electrodes, thin films of copper chloride and copper bromide have been deposited on the surface of copper electrode. In continuation of our study to prepare modified electrodes with copper halides and in order to maintain long-term stability, at this study we reported a sol-gel derived ceramic-carbon composite electrode by the use of copper (I) iodide as modifier.

\section{Results and Discussion}

In this study, CIM-SGD-CCC electrode was prepared and used as a new electrode. Repetitive cyclic voltammograms (CVs) of CIM-SGD-CCC electrode in $0.1 \mathrm{~mol} \mathrm{~L}^{-1} \mathrm{NaOH}$ solution in the range of -250 to $1000 \mathrm{mV}$ (vs. $\mathrm{Ag} / \mathrm{AgCl}$ ) at a scan rate of $50 \mathrm{mVs}^{-1}$ have been shown in Fig. 1.

There are prominent peaks during the first cycle. During the next cycles, however, featureless voltammograms were recorded. This indicates that an irreversible electrochemical transformation of the $\mathrm{CuI}$ has been achieved during the cyclic voltammetry. It seems that a film of oxy copper iodide is formed at the surface of electrode during the cyclic voltammetry step, according to the following reaction: ${ }^{1,17}$

$2 \mathrm{CuI}+2 \mathrm{OH}^{-} \longrightarrow(\mathrm{ICu})_{2} \mathrm{O}+\mathrm{H}_{2} \mathrm{O}+2 \mathrm{e}$

Cyclic voltammetry was used to examine the electro-catalytic efficiency of the CIM-SGD-CCC electrode for the oxidation of hydrazine. Fig. 2 illustrates the CVs of $10^{-3} \mathrm{~mol} \mathrm{~L}^{-1}$ hydrazine at the bare (b) and copper iodide modified (d) sol-gel derived ceramic-carbon composite electrodes in $0.1 \mathrm{~mol} \mathrm{~L}^{-1} \mathrm{NaOH}$ solution at $50 \mathrm{mVs}^{-1}$ in a potential range of -250 to $1000 \mathrm{mV}$ versus $\mathrm{Ag} / \mathrm{AgCl}$. 
At the bare electrode, hydrazine shows a featureless voltammogram. But at the copper iodide modified sol-gel derived ceramic-carbon composite electrode, a large anodic peak appears at $385 \mathrm{mV}$.

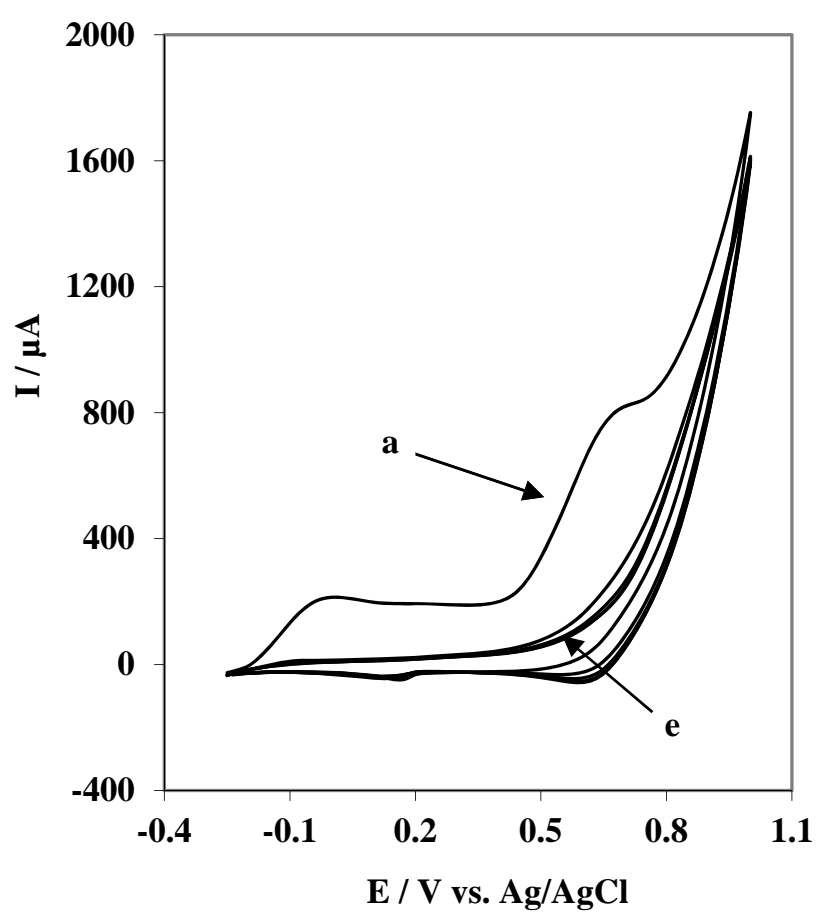

Fig. 1. Repetitive cyclic voltammograms of CIM-SGD-CCC electrode in $0.1 \mathrm{~mol} \mathrm{~L}^{-1} \mathrm{NaOH}$ in the potential range of $-250-1000 \mathrm{mV}$. Potential sweep rate is $50 \mathrm{mV} \mathrm{s}^{-1}$. (a) First cycle; (e) end cycle

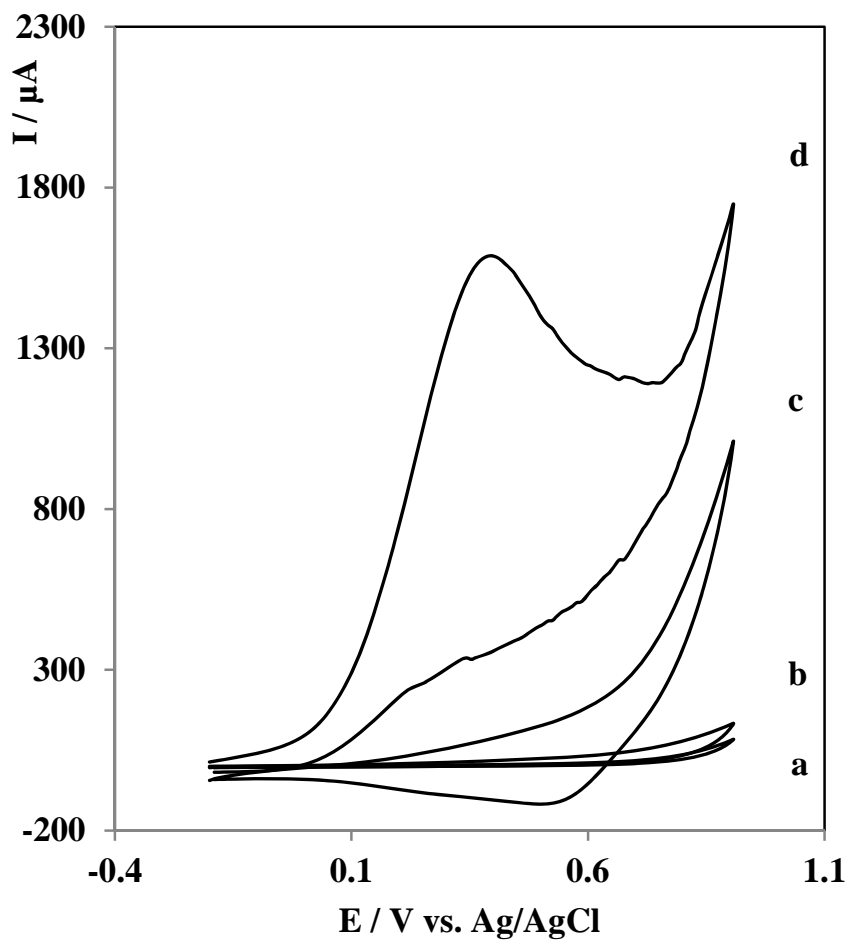

Fig. 2. Cyclic voltammetric responses of bare sol-gel electrode in $0.1 \mathrm{mo}$ $\mathrm{L}^{-1} \mathrm{NaOH}$ solution, without (a) and with $10^{-3} \mathrm{~mol} \mathrm{~L}^{-1}$ hydrazine (b). Cyclic voltammograms of CIM-SGD-CCC electrode in $0.1 \mathrm{~mol} \mathrm{~L}^{-1} \mathrm{NaOH}$ solution in the absence (c) and presence of $10^{-3} \mathrm{~mol} \mathrm{~L}^{-1}$ hydrazine (d). Conditions: scan rate of $50 \mathrm{mV} \mathrm{s}^{-1}$, potential range $-250-1000 \mathrm{mV}$

Comparing (b) and (d) in Fig. 2 shows that at the CIM-SGD-CCC electrode the anodic current of hydrazine oxidation has been greatly enhanced indicating that the anodic oxidation of hydrazine could be catalyzed at CIM-SGD-CCC electrode. This proves that the copper iodide bears the main role in electro-catalytic oxidation of hydrazine. The increased activity probably related to a more favorable adsorption of reactant or of intermediates leading to a higher surface concentration of electroactive molecules ready for being oxidized or it is due to the partial delocalization of the electronic density of hydrazine into the solid with possible consequent bond pre-dissociations which facilitates the oxidation or both.

The amount of copper iodide used for the fabrication of the modified electrode was optimized. The effect of the amount of $\mathrm{CuI}$ on the modification process was ascertained by preparation of the modified electrode with various amounts of $\mathrm{CuI}$, and then, by plotting the peak current as a function of $\mathrm{CuI}$ amount. Results showed that the oxidation current for $10^{-3} \mathrm{~mol} \mathrm{~L}^{-1}$ hydrazine increases gradually with increasing $\mathrm{CuI}$ amount in the range $0.05-0.15 \mathrm{gr}$ and then decreases. Therefore, $0.15 \mathrm{gr}$ $\mathrm{CuI}$ was selected as optimum level in subsequent studies.

Although the exact mechanism was hard to confirm, the first intermediate of hydrazine oxidation in alkaline solutions seems to be $\left[\mathrm{HO}-\mathrm{H}_{2} \mathrm{~N}=\mathrm{NH}_{2}-\mathrm{OH}\right]^{2-}$. Based on the studies reported in literatures ${ }^{2}$ the following mechanism can be proposed for the oxidation of hydrazine in alkaline solutions:

$$
\begin{aligned}
& \mathrm{N}_{2} \mathrm{H}_{4}+2 \mathrm{HO}^{-} \rightarrow\left[\mathrm{HO}-\mathrm{H}_{2} \mathrm{~N}=\mathrm{NH}_{2}-\mathrm{OH}\right]^{2-} \\
& {\left[\mathrm{HO}-\mathrm{H}_{2} \mathrm{~N}=\mathrm{NH}_{2}-\mathrm{OH}\right]^{2-} \rightarrow \mathrm{N}_{2} \mathrm{H}_{2} *+2 \mathrm{H}_{2} \mathrm{O}+2 \mathrm{e}^{-}} \\
& \mathrm{N}_{2} \mathrm{H}_{2} *+2 \mathrm{HO}^{-} \rightarrow \mathrm{N}_{2}+*+2 \mathrm{H}_{2} \mathrm{O}+2 \mathrm{e}^{-}
\end{aligned}
$$


In Eq. (4), the star designates an adsorbed species or a free adsorption site of $(\mathrm{ICu})_{2} \mathrm{O}$. Fig. 3A shows a cyclic voltammogram of the CIM-SGD-CCC electrode at various scan rates obtained in 0.1 mol L ${ }^{-1} \mathrm{NaOH}$ containing $10^{-3} \mathrm{~mol} \mathrm{~L}^{-1}$ hydrazine. It can be noted from this figure that, with an increasing scan rate, the peak potential for the catalytic oxidation of the hydrazine shifts to more positive potentials, suggesting a kinetic limitation in the reaction between the redox sites of the modifier and the hydrazine. However, the peak current for the anodic oxidation of the hydrazine is proportional to the scan rate at high scan rates (Fig. 3B); which is an indication of a adsorptioncontrolled reaction.

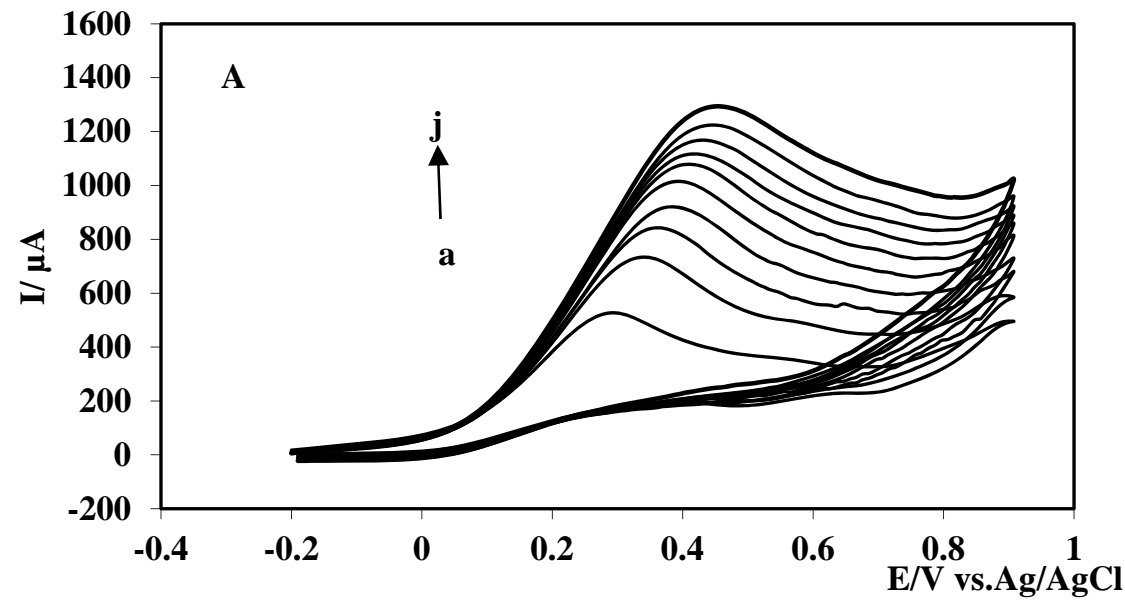

Fig. 3A.

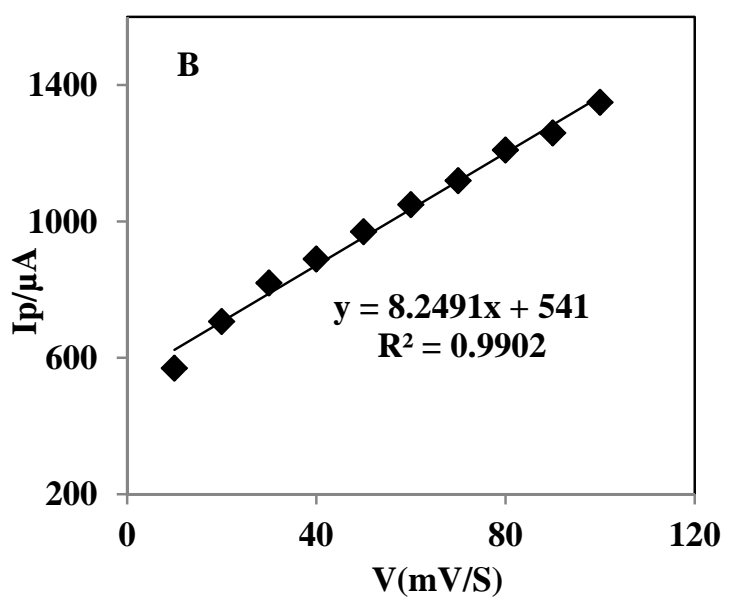

Fig. 3B.

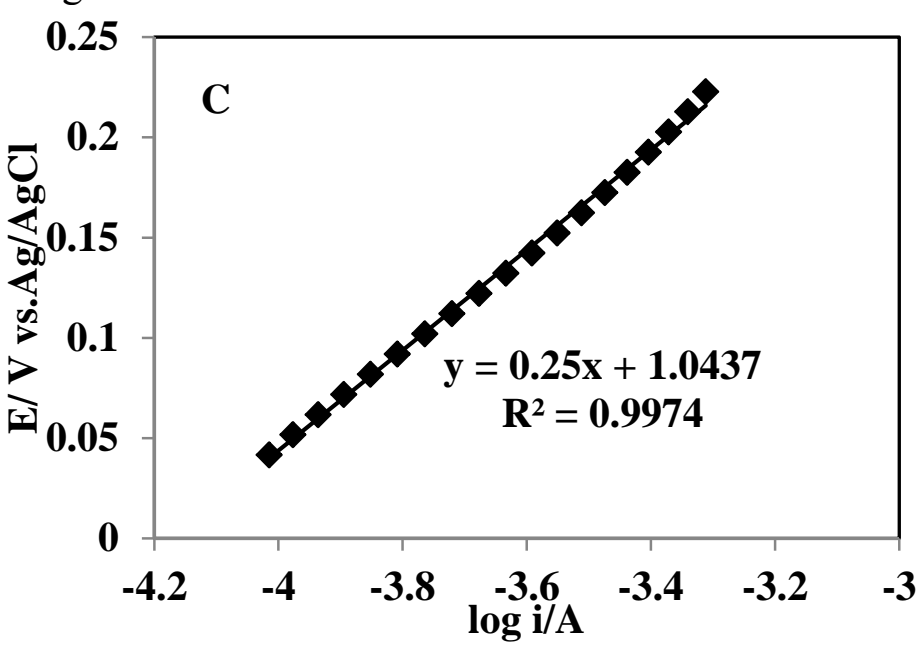

Fig. 3C.

Fig. 3. (A) Dependence of the cyclic voltammetric response at a CIM-SGD-CCC electrode on sweep rate in $0.1 \mathrm{~mol} \mathrm{~L}^{-1} \mathrm{NaOH}$ containing $10^{-3} \mathrm{~mol} \mathrm{~L}^{-1}$ hydrazine. (a)- (j): Scan rate: 10, 20, 30, 40, 50, 60, 70, 80, 90, 100 $\mathrm{mV} \mathrm{s}^{-1}$. (B) Variation of the catalytic current with the sweep rate. (C) Plot of E vs. $\log \mathrm{i}$

To obtain information on the rate-determining step, a Tafel plot (Fig. 3C) was drawn from data of the rising part of the current-voltage curve at a low scan rate of $20 \mathrm{mV} \mathrm{s}^{-1}$. A slope of 199.57 $\mathrm{mVdecade}^{-1}$ is obtained indicating the one-electron transfer to be rate limiting assuming an anodic electron-transfer coefficient of $\alpha=0.76$.

Fig. 4A shows the effect of hydrazine concentration on the cyclic voltammograms of the CIMSGD-CCC electrode. As can be seen from Fig. 4A, the height of the anodic peak increases with increasing hydrazine concentration. The calibration curve obtained from these voltammograms is shown in Fig.4B. There is a good linear relationship between the oxidation peak current and the hydrazine concentration in the range of $2 \times 10^{-4}$ to $12 \times 10^{-4} \mathrm{~mol} \mathrm{~L}^{-1}$. 


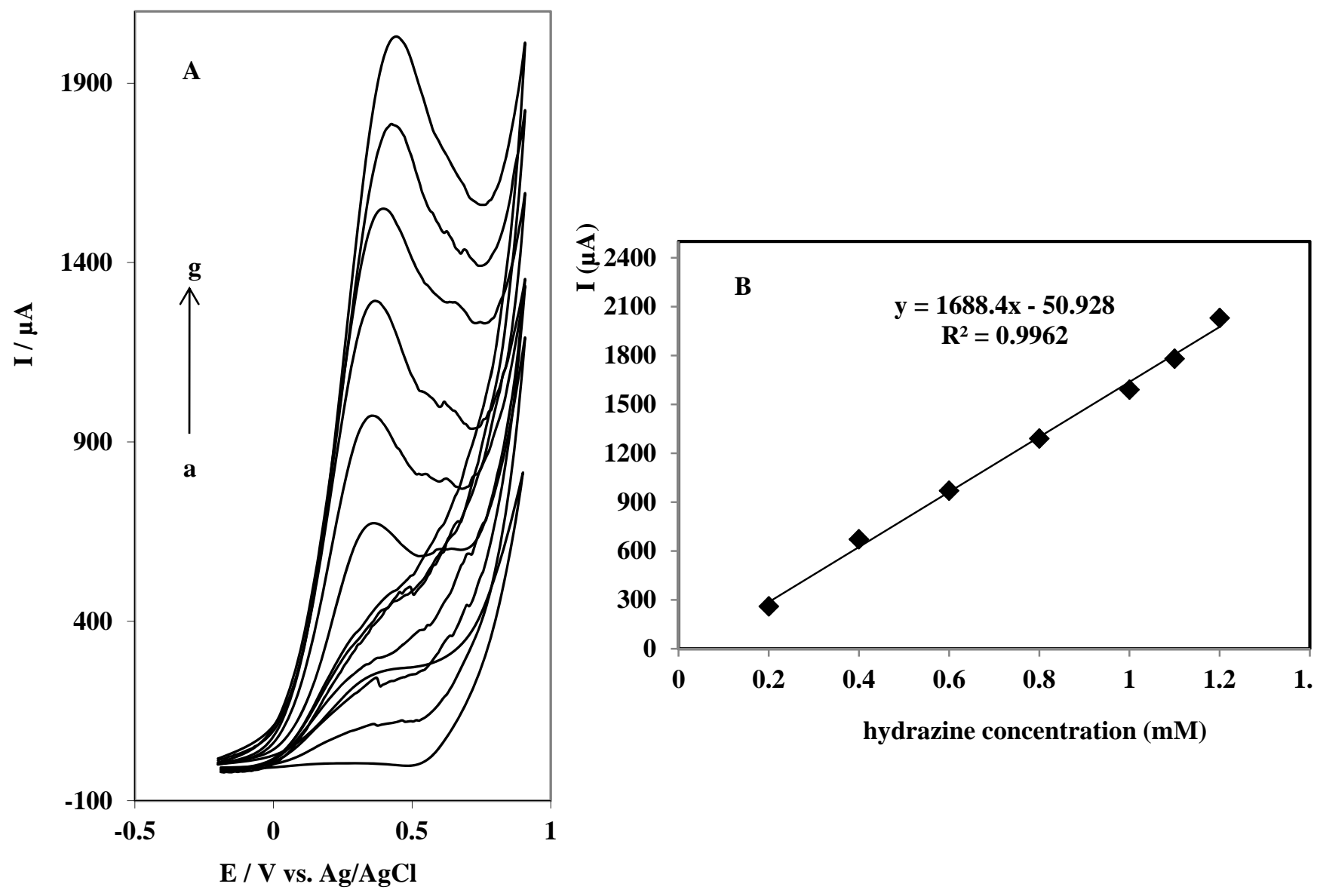

Fig. 4A.

Fig. 4B.

Fig. 4. (A) Cyclic voltammograms of a CIM-SGD-CCC electrode in the presence of various hydrazine concentrations: (a) $-(\mathrm{g}): 2,4,6,8,10,11$, and $12\left(\times 10^{-4}\right) \mathrm{mol} \mathrm{L}^{-1}$ respectively, at a scan rate of $100 \mathrm{mV} \mathrm{s}^{-1}$, in $0.1 \mathrm{~mol} \mathrm{~L}^{-1} \mathrm{NaOH}$ solution. (B) Variation of anodic peak current vs. hydrazine concentration

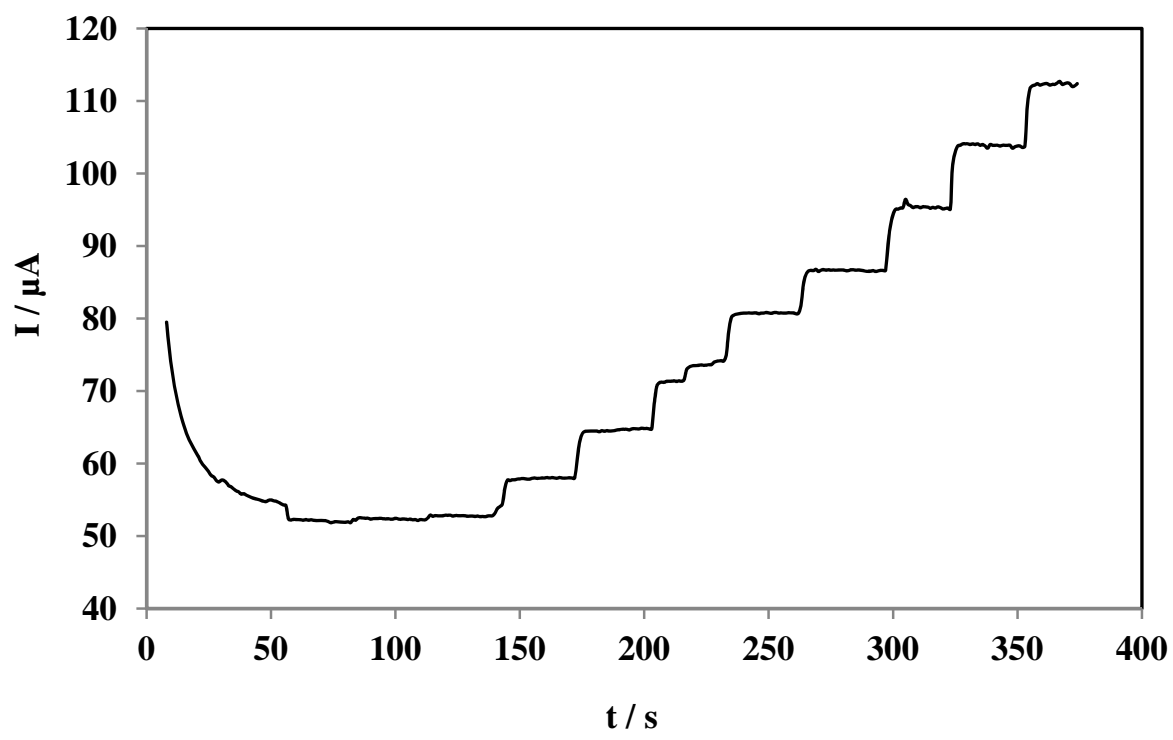

Fig. 5A 


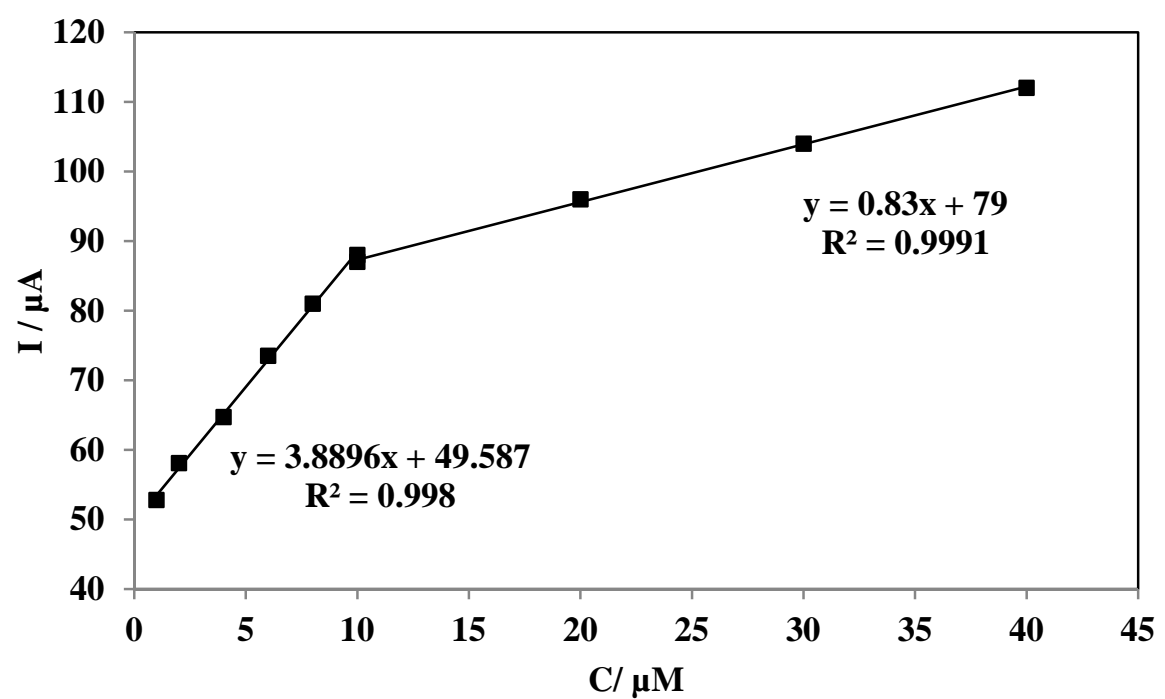

Fig. 5B

Fig. 5. (A) Amperometric response of the CIM-SGD-CCC electrode kept in $600 \mathrm{mV}$ in $0.1 \mathrm{~mol} \mathrm{~L}^{-1} \mathrm{NaOH}$, containing different concentrations of hydrazine from 1 to $40 \mu \mathrm{mol} \mathrm{L}^{-1}$. (B) Calibration plot for concentrations of hydrazine

Fig. 5A shows the effect of concentration of the hydrazine on the amperograms of the CIM-SGD$\mathrm{CCC}$ electrode when the potential was kept at $0.36 \mathrm{~V}$ during the successive addition of hydrazine. Fig. 5B shows that the plot of $I_{p}$ versus hydrazine concentration between $1 \mu \mathrm{mol} \mathrm{L}^{-1}$ and $40 \mu \mathrm{mol} \mathrm{L}^{-}$ 1 consists of two linear segments with different slopes, corresponding to two different ranges of hydrazine concentration. We ascribe these to a change in the reaction conditions arising from the formation of nitrogen gas bubbles at the surface of the electrode, as has already been reported ${ }^{8}$. Indeed at low concentrations of hydrazine, the gas formed, being negligible has no effect on the diffusion of hydrazine toward the electrode surface. However, at high concentrations of hydrazine, gas evolution at the electrode surface reduces to some extent the normal diffusion of the substrate. The calibration plot gives a limit of detection (LOD) of $0.524 \mu \mathrm{mol} \mathrm{L} \mathrm{L}^{-1}$. The repeatability of the response current of the CIM-SGD-CCC electrode was investigated at various hydrazine concentrations. The relative standard deviation (R.S.D.) was $0.72 \%$ for 5 successive assays.

The influence of a number of potential interferents on the determination of hydrazine was studied under the optimum conditions. The tolerance limit was defined as the maximum concentration of the interfering species that cause an error less than $5 \%$ for determination of hydrazine. It was found that 50-fold excesses of $\mathrm{Na}^{+}, \mathrm{K}^{+}, \mathrm{NH}_{4}{ }^{+}, \mathrm{Mg}^{2+}, \mathrm{SO}_{4}{ }^{2-}, \mathrm{NO}_{3}{ }^{-}, \mathrm{CH}_{3} \mathrm{COO}^{-}, \mathrm{Cl}^{-}, \mathrm{Br}^{-}$, methanol, ethanol, glucose, lactose and fructose did not interfere with the determination of hydrazine. These results indicate that the CIM-SGD-CCC electrode has good selectivity for the determination of hydrazine.

In order to check the validity of the proposed electrode for the determination of hydrazine, drinking, river and rain water samples were spiked with $20 \mu \mathrm{mol} \mathrm{L}^{-1}$ of hydrazine and were analyzed under optimized conditions. Acceptable recoveries of hydrazine were obtained with RSDs less than $4 \%(n=3)$.

\section{Conclusion}

Copper iodide modified sol-gel derived ceramic-carbon composite (CIM-SGD-CCC) electrode was prepared as a new electrode and used for electrocatalytic oxidation of hydrazine. The CIM-SGD$\mathrm{CCC}$ electrode exhibits good electrocatalytic activity towards hydrazine. In comparison with the data on the bare sol-gel derived ceramic-carbon composite electrode, an increase in peak current of 
hydrazine was observed at the CIM-SGD-CCC electrode. This proves that the copper iodide bears the main role in electro-catalytic oxidation of hydrazine.

\section{Experimental}

\subsection{Materials and Methods}

Hydrazine and other reagents were of analytical grade supplied by Merck (Darmstadt, Germany) and were used without further purification. All solutions were prepared with doubly distilled water. Electrochemical measurements were carried out in a conventional three-electrode cell powered by an electrochemical system comprising an AUTOLAB system with PGSTAT12 boards (Eco Chemie, Utrecht, The Netherlands). The system was run on a PC using GPES 4.9 softwares. CIM-SGD-CCC electrode as working electrode (prepared as follows) was employed for the electrochemical studies. A platinum wire was employed as counter electrode and an $\mathrm{Ag}, \mathrm{AgCl}$ electrode served as the reference electrode. All experiments were performed at room temperature of $25 \pm 2{ }^{\circ} \mathrm{C}$.

\subsection{General procedure}

The fabrication of CIM-SGD-CCC electrode is described as follows. At the first step a solution of $0.9 \mathrm{ml}$ methanol, $0.6 \mathrm{ml}$ methyltrimethoxysilane (MTMOS), and $0.1 \mathrm{ml}$ hydrochloric acid was mixed and stirred for $2 \mathrm{~min}$ to ensure uniform mixing. Then $0.3 \mathrm{~g}$ graphite powder and $0.15 \mathrm{~g} \mathrm{CuI}$ powder were added and the mixture was shaken for an additional $5 \mathrm{~min}$. The mixture was added into Teflon tubes (with $2 \mathrm{~mm}$ inner diameter and $5 \mathrm{~cm}$ length, and the length of composite material in the tube was about $0.5 \mathrm{~cm}$ ) and dried for $24 \mathrm{~h}$ at room temperature. At the second step the electrode was polished with polishing paper. Then, the electrode was placed in $0.1 \mathrm{~mol} \mathrm{~L}^{-1} \mathrm{NaOH}$ and the electrode potential was cycled between -250 and $1000 \mathrm{mV}$ (vs. $\mathrm{Ag} / \mathrm{AgCl}$ ) at a scan rate of $50 \mathrm{mVs}^{-1}$ for 5 cycles in a cyclic voltammetry regime until a featureless voltammogram was obtained. Electric contacts were made with copper wire through the back of the electrodes. The electrode was rinsed with distilled water, and applied for electrochemical studies.

\section{References}

1. Karim-Nezhad G., Zare Dizajdizi B., and Seyed Dorraji P.(2011) Electrocatalytic oxidation of ethanol at copper bromide modified copper electrode in comparison to bare and copper chloride modified copper electrodes. Catal. Commun., 12 ,906-909.

2. Karim-Nezhad G., and Seyed Dorraji P.(2010) Copper chloride modified copper electrode: Application to electrocatalytic oxidation of methanol. Electrochim. Acta.,55, 3414-3420.

3. Leech D., Wang J., and Shysmth M.R.(1990) Voltammetric behavior of copper(I) oxide modified carbon paste electrode in the presence of cysteine and ascorbic acid. Analyst., 115, 1447-1450.

4. Dong S., and Che G. (1991) Electrocatalysis at a microdisk electrode modified with a redox species. Electroanal. Chem., 309, 103-114.

5. Karim-Nezhad G., Hasanzadeh M., Saghatforoush L.A., Shadjou N., Khalilzadeh B., and Ershad

(2009) Electro-oxidation of ascorbic acid catalyzed on cobalt hydroxide-modified gla ssy carbon electrode. J. Serb. Chem. Soc., 74, 581-593.

6. Wang J., and Golden T.(1989) Permselectivity and ion-exchange properties of Eastman-AQ polymers on glassy carbon electrodes. Anal. Chem. 61, 1397-1400.

7. Shiu K.K., Chan O.Y., and Pang S.K. (1995) Factors affecting the electroanalytical behavior of polypyrrole-modified electrodes bearing complexing ligands. Anal. Chem., 67, 2828-2834. 
8. Karim-Nezhad G., Jafarloo R., and Seyed Dorraji P. (2009) Copper (hydr) oxide modified copper electrode for electrocatalytic oxidation of hydrazine in alkaline media. Electrochim. Acta., 54 ,5721-5726.

9. Salimi A., Abdi K., and Khayatiyan G.R.(2004) Preparation and electrocatalytic oxidation properties of a nickel pentacyanonitrosylferrate modified carbon composite electrode by twostep sol-gel technique: improvement of the catalytic activity. Electrochim. Acta., 49, 413-422.

10. Salazar-Banda G.R., Suffredini H.B., Avaca L.A., and Braz J.(2005) Improved Stability of PtOx Sol-Gel-Modified Diamond Electrodes Covered with a Nafion ${ }^{\circledR}$ Film. Chem. Soc., $16,903-906$.

11. Farhadi Kh., Kheiri F., and Golzan M.M. (2008) Electrochemical properties of Th(IV)Hexacyanoferrate Sol-Gel carbon composite electrode:electrocatalytic oxidation of dopamine and ascorbic acid. J. Chin. Chem. Soc. ,55, 1034-1041.

12. Pauliukaite R., and Brett Ch. M.A.(2005) Characterization of novel glucose oxysilane sol-gel electrochemical biosensors with copper hexacyanoferrate mediator. Electrochim. Acta.,50,4973-4980.

13. Florescu M., Barsan M., Pauliukaite R., and Brett Ch. M.A. (2007) Development and application of Oxysilane Sol-Gel electrochemical Glucose biosensors based on Cobalt Hexacyanoferrate modified Carbon film electrodes. Electroanalysis., 19, 220-226.

14. Cox J.A., Jaworski R., and Kulesza P.J. (1991) Electroanalysis with electrodes modified by inorganic films. Electroanalysis., 3 , 869-877.

15. Pournaghi-Azar M.H., and Razmi-Nerbin H. (2000) Electrocatalytic characteristics of ascorbic acid oxidatio at nickel plated aluminum electrodes modified with nickel pentacyanonitrosylferrate films. J. Electroanal. Chem. ,488, 17-24.

16. Monk P. M. S., Mortimer R. J., and Rosseinsky D. R. (1995) Electrochromism: Fundamentals and Applications, VCH, Weinheim, Germany ,2531,135-142.

17. Djozan D.j., Assadi Y., and Karim-Nezhad G. (2002) Modified copper wire as solid-phase microextraction fiber, selective extraction of some amines. Chromatographia., 56, 611616. 